\title{
The effect of preoperative smoking cessation and smoking dose on postoperative complications following radical gastrectomy for gastric cancer: a retrospective study of 2469 patients
}

\author{
Hu Quan ${ }^{1+}$, Linda Ouyang ${ }^{2 \dagger}$, Huijun Zhou ${ }^{3}$, Yongzhong Ouyang ${ }^{1}$ and Hua Xiao ${ }^{1 *}$ (D)
}

\begin{abstract}
Background: To investigate whether smoking adversely affects the short-term outcomes and the potential effects of cigarette dose and preoperative smoking cessation, in patients who underwent gastric cancer (GC) surgery.

Methods: Two thousand, four hundred sixty-nine consecutive patients who underwent radical gastrectomy from November 2010 to July 2018 were included in the present study. Smokers (current or former smokers) were divided into 3 groups in accordance with the duration of smoking cessation preoperatively ( $\leq 2,2$ to 4 , or $\geq 4$ weeks) and the cigarette dose ( $\leq 20,20$ to 40 , and $\geq 40$ pack-years). The primary endpoint was postoperative complications (surgical site infection, pulmonary problems, bleeding, and others).

Results: A total of 1056 patients (42.8\%) were smokers. Compared with non-smokers, smokers had significantly higher overall postoperative complications $(11.3 \%$ vs $7.5 \%, P=0.001)$, and in particular pulmonary problems. Smokers also had more major complications, needing intensive care unit care, and longer postoperative hospital stays. Multivariate analysis confirmed that smoking (odds ratio $=1.506,95 \%$ confidence interval $1.131-2.004, P=0.005$ ) was an independent risk factor for postoperative complications. Further subgroup analysis identified that there was a positive relationship between the incidence of complications and cigarette dose, and $>20$ pack-years was demonstrated to have increased significantly the risk of complications. Smokers who stopped smoking $\geq 4$ weeks before surgery had lower pulmonary problems than those with a shorter period of smoking cessation.

Conclusions: Preoperative smoking cessation should be encouraged to reduce postoperative complications in GC patients, especially for heavy smokers.
\end{abstract}

Keywords: Gastric cancer, Gastrectomy, Postoperative complication, Cigarette smoking, Smoking cessation

\section{Background}

Gastric cancer (GC) is ranked as one of the most prevalent malignancies worldwide with about one half of cases occurring in China. At present, curative resection is the only mainstay of therapy $[1,2]$. Despite a downward trend in the incidence of postoperative complications

\footnotetext{
* Correspondence: huakexh2010@163.com

${ }^{\dagger} \mathrm{Hu}$ Quan and Linda Ouyang contributed equally to this work.

'Department of Gastroduodenal and Pancreatic Surgery, Hunan Cancer Hospital and the Affiliated Cancer Hospital of Xiangya School of Medicine, Central South University, No. 283 Tongzipo Road, Changsha 410013, China Full list of author information is available at the end of the article
}

following gastrectomy, due to significant improvements in surgical techniques, about $10.3-23.6 \%$ of patients experienced morbidity, resulting in longer hospital stays, increased healthcare costs, and even perioperative death [3-6]. In order to reduce postoperative complications and improve the patients' quality of life, it is essential to identify potential risk factors and those patients at high risk. To date, various factors have been identified as adverse predictors for morbidity after gastrectomy, such as advanced age, obesity, and blood transfusion $[3,5,6]$. Unfortunately, most of these factors are not modifiable

(c) The Author(s). 2019 Open Access This article is distributed under the terms of the Creative Commons Attribution 4.0 International License (http://creativecommons.org/licenses/by/4.0/), which permits unrestricted use, distribution, and 
[7]. There is growing evidence that smoking is a significant risk factor for postoperative complications following a variety of operations, especially pulmonary problems and surgical site infections [8-11]. As a result, quitting smoking before surgery is likely to improve the short-term outcomes [12]. Other scholars have argued that cessation of smoking shortly before surgery will not decrease postoperative complications [13, 14]. Possible explanations for the conflicting data were the variable duration of smoking cessation before surgery and inconsistency in patient inclusion criteria.

In fact, most of the previous studies were conducted in patients who underwent thoracic surgery or taking varied abdominal surgery procedures together. But in fact, the incidence and risk factors for postoperative pulmonary problems following lower and upper abdominal surgery may differ significantly. For example, patients who underwent hepatobiliary and upper gastrointestinal surgery were twice as likely to develop pulmonary complications than those from any other surgical categories [15]. Thus, to reduce postoperative complications, it is important to understand the incidence and risk factors for complications for each type of surgical procedure. To our knowledge, no study has focused solely on GC patients and the influence of cigarette dose on postoperative complications following gastrectomy has not been investigated [16]. We hypothesize that smoking may serve as an independent risk factor for postoperative complications following radical gastrectomy for GC, especially pulmonary problems, and there may be a dose-dependent effect between cigarette dose and the incidence of complications, and an optimal duration of smoking cessation preoperatively could reduce its incidence. This question was addressed by conducting a retrospective study to investigate the potential influence of smoking, cigarette dose, and the duration of smoking cessation prior to surgery on the incidence of postoperative complications in GC patients who underwent radical gastrectomy.

\section{Methods}

\section{Design and patients}

We retrospectively reviewed the medical record of all adult patients with GC who underwent operation in our hospital from November 2010 to July 2018. Exclusion criteria are described in Fig. 1. A total of 2469 consecutive patients were included in the present study. The smoking history of each patient was established by the responsible doctor on admission. Patients were divided into two groups, namely smokers and non-smokers according to their answers. For smokers, the average pack of cigarette smoked everyday and the number of years of smoking were recorded. All smokers were instructed to quit smoking immediately when they were admitted.
Active and passive smoking was strictly prohibited for all patients during their hospital stay. The present study was approved by the ethics committee of our hospital, and informed consent was waived considering it is a retrospective investigation and observational in nature. The clinicopathological factors including baseline demographics, preoperative laboratory measurements, intraoperative variables, and pathological tumor characteristics (based on AJCC 8th edition [17]) were evaluated.

\section{Surgical procedures and perioperative management}

Gastrointestinal surgeons with sufficient experience of curative radical gastrectomy performed or supervised all operations. Lymphadenectomy and digestive tract reconstruction were performed in accordance with the Japanese gastric cancer treatment guidelines [18]. As described in our previous studies $[6,19]$, for patients with locally advanced GC, open procedure with D2 or D2+ (no. 8p, 12p, 13, and/or 14v lymph nodes) lymphadenectomy was the main surgical type and all of the procedure was performed by a midline incision. But no patients were performed with D3 lymphadenectomy in the present study. While for those with early GC, total laparoscopy or laparoscopy-assisted gastrectomy with $\mathrm{D} 1+\alpha$ or $\beta$ lymphadenectomy was performed. Combined multi-organ resection was carried out in patients with a locally advanced tumor with potential invasion of nearby organs to achieve R0 resection, or resection of other organs due to simultaneously occurring benign disease. A second- or third-generation cephalosporin was used as a prophylactic antibiotic in all patients and administered for 3 to 5 days after surgery. The nasogastric tube was usually removed on postoperative day 1 , but was left in place for about 3 days until anal exhaust occurred in some patients with severe edema of the stomach because of pyloric obstruction.

\section{Definitions}

Smokers were defined as current or former smokers, and non-smokers were considered to be those who had never previously smoked. Smokers were divided into three categories depending on their smoking cessation period before surgery ( $\leq 2,2$ to 4 , and $\geq 4$ weeks), as reported for the majority of previous similar studies $[12,15,20-22]$. The cigarette dose was calculated by the average number of packs of cigarettes smoked everyday multiplied by the duration of smoking years (pack-years). In addition, smokers were subsequently classified into 3 subgroups according to the 25th and 75th cigarette dose, indicating light, moderate, and heavy smokers (20 and 40 pack-years in the present study, respectively), similar to but not exactly the same with a previous study, in which pack-year was divided into quartiles [9]. 


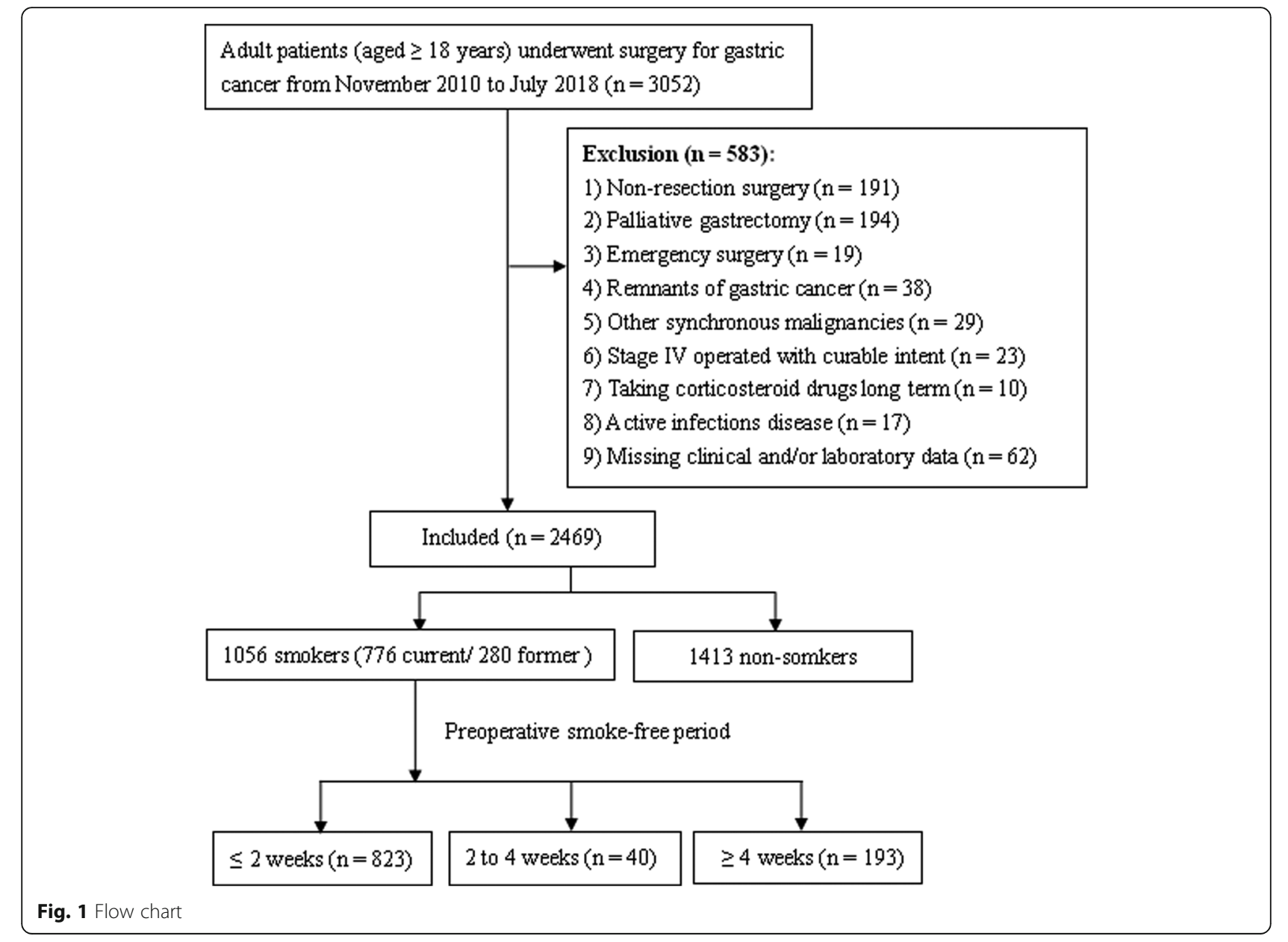

Postoperative complications were noted for $\leq 30$ days following surgery and classified according to the ClavienDindo classification [23]. As reported by Aoyama et al. [24], grade I complications were excluded as they are considered to have little clinical significance. Major complications were defined as Clavien-Dindo grade III or greater. In some patients who suffered from more than one complication, each of the complications was recorded and analyzed.

\section{Statistical analysis}

All patients were classified into two groups according to whether they had ever smoked or not. Differences between the groups were compared by univariate analyses, a $\chi 2$ or Fisher's exact test for categorical variables. The test data for normal distribution was checked by the Shapiro-Wilk test, and a Student $t$ test or Mann-Whitney $U$ test was used for continuous data which was normally distributed or not. Continuous and multiclassification categorical variables were converted into binary outcomes according to the standard clinical or widely accepted thresholds, as reported in our previous studies $[6,19]$. Univariate analysis by a $\chi^{2}$ test was carried out to test the impact of clinicopathological variables on postoperative complications. Multivariate binary logistic regression analysis (forward: LR) was further used to test factors with a $P$ value $<0.05$ following univariate analysis. The prognostic performance of the model was evaluated by the area under the curve (AUC) for the receiver operator characteristic (ROC) plot. Subgroup analysis was performed basing on the smoking cessation period before surgery and the pack-years and was compared with the non-smoker group as the reference using logistic regression analysis. All statistical analyses were performed with IBM SPSS Statistics for Windows (Version 24, NY: IBM Corporation, US), and a $P$ value $<0.05$ was considered to be significant.

\section{Results}

\section{Characteristics of patients}

Baseline demographics of the entire cohort of 2469 patients are described in Table 1. The mean age was 55.44 years (range 19-86), mean body mass index (BMI) was $21.83 \mathrm{~kg} / \mathrm{m}^{2}$ (range 13.84-35.17), and 1625 (65.8\%) of the patients were male. The majority $(74.0 \%)$ underwent distal subtotal gastrectomy, and the remainder underwent 
Table 1 Clinicopathological characteristics of the entire cohort $(n=2469)$

\begin{tabular}{|c|c|c|c|}
\hline Variables & Smokers $(n=1056)$ & Non-smokers $(n=1413)$ & $P$ value \\
\hline Gender (male) & $1042(98.7 \%)$ & $582(41.1 \%)$ & $<0.001$ \\
\hline Age (years) & $57.02 \pm 9.37$ & $54.26 \pm 11.28$ & $<0.001$ \\
\hline Body mass index $\left(\mathrm{kg} / \mathrm{m}^{2}\right)$ & $21.87 \pm 3.00$ & $21.80 \pm 2.98$ & 0.574 \\
\hline ASA score & & & $<0.001$ \\
\hline 1 & $151(14.3 \%)$ & $288(20.4 \%)$ & \\
\hline 2 & $789(74.7 \%)$ & $975(69.0 \%)$ & \\
\hline 3 & $109(10.3 \%)$ & $147(10.4 \%)$ & \\
\hline 4 & $7(0.7 \%)$ & $3(0.2 \%)$ & \\
\hline Any comorbidities & $353(33.4 \%)$ & $384(27.2 \%)$ & 0.001 \\
\hline Chronic obstructive pulmonary disease & $54(5.1 \%)$ & $27(1.9 \%)$ & $<0.001$ \\
\hline Abdominal surgery history & $82(7.8 \%)$ & $180(12.7 \%)$ & $<0.001$ \\
\hline \multicolumn{4}{|l|}{ Pulmonary function test ${ }^{a}$} \\
\hline Predicted vital capacity (\%VC) & $87.36 \pm 19.45$ & $89.95 \pm 20.67$ & 0.004 \\
\hline Forced expiratory volume in $1 \mathrm{~s}$ (FEV1\%) & $87.88 \pm 12.49$ & $90.18 \pm 10.34$ & $<0.001$ \\
\hline Preoperative albumin (g/L) & $38.14 \pm 4.59$ & $38.49 \pm 4.51$ & 0.056 \\
\hline Preoperative hemoglobin ( $\mathrm{g} / \mathrm{L}$ ) & $123.62 \pm 25.56$ & $115.38 \pm 23.34$ & $<0.001$ \\
\hline Complication due to the tumor ${ }^{b}$ & $236(22.3 \%)$ & $298(21.1 \%)$ & 0.452 \\
\hline Operation method & & & 0.539 \\
\hline Open & $808(76.5 \%)$ & $1096(77.6 \%)$ & \\
\hline Laparoscopy & $248(23.5 \%)$ & $317(22.4 \%)$ & \\
\hline Type of resection & & & 0.914 \\
\hline Proximal subtotal gastrectomy & $25(2.4 \%)$ & $36(2.5 \%)$ & \\
\hline Distal subtotal gastrectomy & 779 (73.8\%) & $1048(74.2 \%)$ & \\
\hline Total gastrectomy & $252(23.9 \%)$ & $329(23.3 \%)$ & \\
\hline Extent of lymph node dissection & & & 0.364 \\
\hline$\geq \mathrm{D} 2$ & $998(94.5 \%)$ & $1323(93.6 \%)$ & \\
\hline$<\mathrm{D} 2$ & $58(5.5 \%)$ & $90(6.4 \%)$ & \\
\hline Combined multi-organ resection & $98(9.3 \%)$ & $122(8.6 \%)$ & 0.577 \\
\hline Tumor size (cm) & $4.15 \pm 2.02$ & $4.03 \pm 2.12$ & 0.162 \\
\hline Tumor location & & & $<0.001$ \\
\hline Upper & $113(10.7 \%)$ & $103(7.3 \%)$ & \\
\hline Middle & $211(20.0 \%)$ & $302(21.4 \%)$ & \\
\hline Lower & $713(67.5 \%)$ & 945 (66.9\%) & \\
\hline Diffuse & $19(1.8 \%)$ & $63(4.5 \%)$ & \\
\hline T stage ${ }^{c}$ & & & 0.032 \\
\hline $\mathrm{T} 1$ & $196(18.6 \%)$ & 297 (21.0\%) & \\
\hline $\mathrm{T} 2$ & $167(15.8 \%)$ & $191(13.5 \%)$ & \\
\hline $\mathrm{T} 3$ & $82(7.8 \%)$ & $79(5.6 \%)$ & \\
\hline T4 & 611 (57.9\%) & 846 (59.9\%) & \\
\hline$N$ stage $^{c}$ & & & 0.490 \\
\hline NO & 402 (38.1\%) & 567 (40.1\%) & \\
\hline $\mathrm{N} 1$ & $184(17.4 \%)$ & 225 (15.9\%) & \\
\hline N2 & 208 (19.7\%) & 257 (18.2\%) & \\
\hline N3 & $262(24.8 \%)$ & 364 (25.8\%) & \\
\hline
\end{tabular}


Table 1 Clinicopathological characteristics of the entire cohort $(n=2469)$ (Continued)

\begin{tabular}{|c|c|c|c|}
\hline Variables & Smokers $(n=1056)$ & Non-smokers $(n=1413)$ & $P$ value \\
\hline pTNM stage ${ }^{c}$ & & & 0.890 \\
\hline । & $272(25.8 \%)$ & $376(26.6 \%)$ & \\
\hline$\|$ & $235(22.2 \%)$ & $309(21.9 \%)$ & \\
\hline III & $549(52.0 \%)$ & $728(51.5 \%)$ & \\
\hline Harvested lymph node & $22.70 \pm 8.95$ & $21.30 \pm 8.38$ & $<0.001$ \\
\hline Intraoperative blood loss (mL) & $208.51 \pm 126.73$ & $199.60 \pm 118.58$ & 0.073 \\
\hline Operation time (min) & $203.97 \pm 54.61$ & $195.77 \pm 53.45$ & $<0.001$ \\
\hline Postoperative complications ${ }^{d}$ & $119(11.3 \%)$ & $106(7.5 \%)$ & 0.001 \\
\hline Transferring to ICU postoperation & $33(3.1 \%)$ & $25(1.8 \%)$ & 0.028 \\
\hline Postoperative hospital stays (days) & $11.78 \pm 6.63$ & $11.17 \pm 4.46$ & 0.007 \\
\hline
\end{tabular}

Data are presented as mean \pm SD or $\mathrm{n}(\%)$

ASA American Society of Anesthesiology, ICU intensive care unit

a Data for 395 patients were missing (130 smokers, 265 non-smokers)

${ }^{\mathrm{b}}$ Including pyloric obstruction or bleeding

'Tumor stages are based on the 8th edition of AJCC TNM classification

${ }^{\mathrm{d}}$ Data are no. of patients (\%), patients may have more than one complication

either total (23.5\%) or proximal subtotal $(2.5 \%)$ gastrectomy. Based on the 8th edition of the TNM classification, there were $648(26.2 \%)$ stage I, $544(22.0 \%)$ stage II, and 1277 (51.7\%) stage III patients. The mean duration of surgery was $199.28 \mathrm{~min}$ (range 70-584), and the mean estimated intraoperative bleeding was $203.41 \mathrm{~mL}$ (rang, 30-2300).

One thousand and fifty-six (42.8\%) patients were smokers, with a median cigarette dose of 30 pack-years (range 1-120), and the remaining 1413 cases were non-smokers. As shown in Table 1, smokers were significantly male predominant and of advanced age, with comorbidities (including chronic obstructive pulmonary disease, COPD), worse pulmonary function (smaller predicted vital capacity (\%VC), forced expiratory volume in $1 \mathrm{~s}$ (FEV1\%)), upper third location of the tumor, more harvested lymph nodes, longer operation times, adverse postoperative events, and a higher frequency of requiring intensive care (all $P<0.05$ ). The mean duration of the postoperative hospital stay was also longer than for the non-smoker group (11.78 vs 11.17 days, $P=0.007$ ). It is noteworthy that the type of resection, operation method, pathological TNM stages, and mean BMI and tumor size were comparable between the two groups (all $P>0.05$ ).

\section{Postoperative complications}

Two hundred and ninety-three postoperative adverse events occurred in 220 patients of the entire cohort (8.9\%), with surgical site infections being the most common $(n=116)$, followed by pulmonary complications $(n=$ $100)$, bleeding $(n=24)$, and others $(n=53)$ (see Table 2). Among surgical site infections, organ/space surgical site infection occurred most frequently, including 63 cases of intra-abdominal infections, 26 cases of anastomotic or stump leakage, and so on. With respect to pulmonary problems, pneumonia was the most common, which occurred in 65 patients, with 63 were bacterial and the remaining 2 cases were aspiration. Based on the Clavien-Dindo classification, the incidence of stage II, IIIa, IIIb, IVa, IVb, and V complications was $8.3 \%(n=206)$, $1.3 \%(n=32), 1.3 \%(n=31), 0.6 \%(n=15), 0.04 \%(n=1)$, and $0.3 \%(n=8)$, respectively. Eighty-nine events of major complications ( $\geq$ grade III) occurred in 69 patients.

When comparing the overall incidence of postoperative complications stratified by smoking history, the rate was significantly greater in smokers than in non-smokers $(11.3 \%$ vs $7.5 \%, P=0.001)$. Considering each type of complication, only pulmonary problems were significantly more common in the smoker group. However, the incidence of surgical site infection, bleeding, and other complications was comparable between the two groups. Forty-eight cases of major complications occurred in 39 smokers, which was substantially more frequent than in the non-smoker group (39 cases in 30 patients, $P=0.017$ ).

\section{Risk factors for postoperative complications}

Based on the univariate analysis, postoperative complications were significantly more commonly found in male patients, smokers, aged $\geq 65$ years, and those with an American Society of Anesthesiologists (ASA) score $\geq 3$, any comorbidity, preoperative albumin $<35 \mathrm{~g} / \mathrm{L}$, complications such as bleeding or pyloric obstruction due to the tumor, total gastrectomy, combined multi-organ resection, operation time $\geq 240 \mathrm{~min}$, intraoperative blood loss $\geq 300 \mathrm{~mL}$, lymph node metastasis, pathological TNM stage III, and perioperative blood transfusion (Table 3). After the multivariate analysis of the abovementioned variables, only smoking (odds ratio $[\mathrm{OR}]=1.506$, 95\% confidence interval $[\mathrm{CI}] 1.131-2.004, P=0.005)$, perioperative blood transfusion, operation time $\geq 240 \mathrm{~min}$, combined multi-organ resection, ASA score $\geq 3$, and 
Table 2 Postoperative complications and severity of complications in smokers and non-smokers (293 events in 220 patients)

\begin{tabular}{|c|c|c|c|}
\hline Variables & $\begin{array}{l}\text { Smokers } \\
(n=1056)\end{array}$ & $\begin{array}{l}\text { Non-smokers } \\
(n=1413)\end{array}$ & $P$ value \\
\hline Complications $^{\mathrm{a}}$ & $150(14.2 \%)$ & $143(10.1 \%)$ & 0.002 \\
\hline Surgical site infection & $57(5.4 \%)$ & $59(4.2 \%)$ & 0.156 \\
\hline $\begin{array}{l}\text { Organ/space surgical } \\
\text { site infection }\end{array}$ & $53(5.0 \%)$ & $51(3.6 \%)$ & \\
\hline Would dehiscence & $4(0.4 \%)$ & $8(0.6 \%)$ & \\
\hline Pulmonary complication & $54(5.1 \%)$ & $46(3.3 \%)$ & 0.020 \\
\hline Pneumonia & $32(3.0 \%)$ & $33(2.3 \%)$ & \\
\hline Pleural effusion & $15(1.4 \%)$ & $10(0.7 \%)$ & \\
\hline $\begin{array}{l}\text { Acute respiratory } \\
\text { distress syndrome }\end{array}$ & $2(0.2 \%)$ & 0 & \\
\hline Pneumothorax & $3(0.3 \%)$ & 0 & \\
\hline Atelectasis & $2(0.2 \%)$ & $3(0.2 \%)$ & \\
\hline Bleeding & $12(1.1 \%)$ & $12(0.8 \%)$ & 0.472 \\
\hline Intra-abdominal bleeding & $6(0.6 \%)$ & $9(0.6 \%)$ & \\
\hline Gastrointestinal bleeding & $6(0.6 \%)$ & $3(0.2 \%)$ & \\
\hline Others & $27(2.6 \%)$ & $26(1.8 \%)$ & 0.224 \\
\hline Intestinal obstruction & $12(1.1 \%)$ & $8(0.6 \%)$ & \\
\hline Ascites & $9(0.5 \%)$ & $6(0.4 \%)$ & \\
\hline Cerebral infarction & $2(0.2 \%)$ & $2(0.1 \%)$ & \\
\hline Delayed gastric emptying & $1(0.1 \%)$ & $1(0.1 \%)$ & \\
\hline Anastomotic stricture & 0 & $2(0.1 \%)$ & \\
\hline Liver failure & $1(0.1 \%)$ & $1(0.1 \%)$ & \\
\hline Urinary tract infection & $1(0.1 \%)$ & $1(0.1 \%)$ & \\
\hline Cardiac arrest & $1(0.1 \%)$ & $1(0.1 \%)$ & \\
\hline Urinary retention & 0 & $2(0.1 \%)$ & \\
\hline Diabetic ketoacidosis & 0 & $1(0.1 \%)$ & \\
\hline Renal failure & 0 & $1(0.1 \%)$ & \\
\hline Severity of complications ${ }^{b}$ & & & 0.005 \\
\hline Minor (grade II) & $102(9.8 \%)$ & $104(7.4 \%)$ & \\
\hline Major (grade III or greater) & $48(4.5 \%)$ & $39(2.8 \%)$ & \\
\hline Grade IIla & $17(1.6 \%)$ & $15(1.1 \%)$ & \\
\hline Grade IIIb & $18(1.7 \%)$ & $13(0.9 \%)$ & \\
\hline Grade IVa & $8(0.8 \%)$ & $7(0.5 \%)$ & \\
\hline Grade IVb & 0 & $1(0.1 \%)$ & \\
\hline Grade V & $5(0.5 \%)$ & $3(0.2 \%)$ & \\
\hline
\end{tabular}

${ }^{a}$ Data are number of complications (\%), patients may have more than one complications ${ }^{\mathrm{b}}$ Based on the Clavien-Dindo severity classification of surgical complications

comorbidity were significant predictors for postoperative complications (Table 4). Some other well-known variables, such as the extent of lymphadenectomy and total gastrectomy, were not identified to be independent risk factors in the present study, may be due to the relatively small proportion of patients who underwent < D2 lymphadenectomy and low incidence of postoperative complications. In
Table 3 Univariate analysis of possible predictors for postoperative complications following radical gastrectomy for gastric cancer $(n=2469)$

\begin{tabular}{|c|c|c|c|}
\hline Variables & $\begin{array}{l}\text { Complications } \\
(n=225)\end{array}$ & $\begin{array}{l}\text { Non-complications } \\
(n=2244)\end{array}$ & $P$ value \\
\hline Sex (male/female) & $165 / 60$ & $1459 / 785$ & 0.012 \\
\hline Age (years) $\geq 65 /<65$ & $64 / 161$ & $451 / 1793$ & 0.003 \\
\hline $\begin{array}{l}\text { Body mass index }\left(\mathrm{kg} / \mathrm{m}^{2}\right) \\
\geq 25 /<25\end{array}$ & $41 / 184$ & $310 / 1934$ & 0.071 \\
\hline Smoking history; yes/no & 119/106 & $937 / 1307$ & 0.001 \\
\hline ASA score $\geq 3 /<3$ & $44 / 181$ & $222 / 2022$ & $<0.001$ \\
\hline $\begin{array}{l}\text { Abdominal surgical } \\
\text { history; yes/no }\end{array}$ & $31 / 194$ & $231 / 2013$ & 0.106 \\
\hline Comorbidity; yes/no & $87 / 138$ & $650 / 1594$ & 0.002 \\
\hline $\begin{array}{l}\text { Chronic obstructive } \\
\text { pulmonary disease }\end{array}$ & $12 / 213$ & $69 / 2175$ & 0.070 \\
\hline $\begin{array}{l}\text { Preoperative albumin } \\
(\mathrm{g} / \mathrm{L}) \geq 35 /<35\end{array}$ & $151 / 74$ & $1783 / 461$ & $<0.001$ \\
\hline $\begin{array}{l}\text { Complication due to } \\
\text { the tumor }{ }^{a} ; \text { yes } / \text { no }\end{array}$ & $69 / 156$ & $465 / 1779$ & 0.001 \\
\hline $\begin{array}{l}\text { Operation method; } \\
\text { open/laparoscopy }\end{array}$ & $185 / 40$ & $1719 / 525$ & 0.056 \\
\hline $\begin{array}{l}\text { Extent of gastric } \\
\text { resection; subtotal/total }\end{array}$ & $158 / 67$ & $1730 / 514$ & 0.021 \\
\hline $\begin{array}{l}\text { Extent of lymph node } \\
\text { dissection } \geq \mathrm{D} 2 /<\mathrm{D} 2\end{array}$ & $213 / 12$ & $2108 / 136$ & 0.661 \\
\hline $\begin{array}{l}\text { Combined multi-organ } \\
\text { resection; yes/no }\end{array}$ & $43 / 182$ & $177 / 2067$ & $<0.001$ \\
\hline $\begin{array}{l}\text { Operation time (min) } \\
\geq 240 /<240\end{array}$ & $87 / 138$ & $447 / 1797$ & $<0.001$ \\
\hline $\begin{array}{l}\text { Intra-operative blood } \\
\text { loss }(\mathrm{mL}) \geq 300 /<300\end{array}$ & $59 / 166$ & $435 / 1809$ & 0.015 \\
\hline $\begin{array}{l}\text { Lymph node metastasis; } \\
\text { positive/negative }\end{array}$ & $154 / 71$ & $1346 / 898$ & 0.013 \\
\hline pTNM stage ${ }^{b} ;\|I / /-I\|$ & $135 / 90$ & $1142 / 1102$ & 0.009 \\
\hline $\begin{array}{l}\text { Perioperative blood } \\
\text { transfusion; yes/no }\end{array}$ & $96 / 129$ & 409/1835 & $<0.001$ \\
\hline
\end{tabular}

ASA American Society of Anesthesiologist

aIncluding pyloric obstruction or bleeding

${ }^{\text {b}}$ Tumor stages are based on the 8th edition of AJCC TNM classification

the internal validation of the predictive model by ROC plot, the AUC value was found to be 0.701 (95\% CI 0.662-0.739), indicating that the predictive ability of the present model was good.

\section{Subgroup analysis}

Patients in the smoker group were classified into three subgroups depending on the duration of the smoking cessation period prior to surgery. The incidence rate of postoperative complications was also investigated for each group (Table 5). The incidence of overall complications among smokers who ceased smoking $\leq 2$ weeks, 2 to 4 weeks, and $\geq 4$ weeks preoperatively were $14.0 \%$, $15.0 \%$, and $15.0 \%$, respectively, which were significantly 
Table 4 Multivariate analysis of possible predictors for postoperative complications following radical gastrectomy for gastric cancer $(n=2469)$

\begin{tabular}{lcll}
\hline Variables & Odds ratio (OR) & $\begin{array}{l}95 \% \text { Confidence } \\
\text { interval }(\mathrm{Cl})\end{array}$ & $P$ value \\
\hline $\begin{array}{l}\text { Perioperative blood } \\
\text { transfusion }\end{array}$ & 2.753 & $2.038-3.719$ & $<0.001$ \\
$\begin{array}{l}\text { Operation time } \\
\geq 240 \text { min }\end{array}$ & 2.037 & $1.500-2.764$ & $<0.001$ \\
$\begin{array}{l}\text { Combined multi-organ } \\
\text { resection }\end{array}$ & 1.767 & $1.184-2.638$ & 0.005 \\
$\begin{array}{l}\text { Smoking history } \\
\text { ASA score } \geq 3\end{array}$ & 1.506 & $1.131-2.004$ & 0.005 \\
Any comorbidity & 1.687 & $1.152-2.470$ & 0.007 \\
\hline ASA Amercan Socity & 1.362 & $1.010-1.838$ & 0.043 \\
\hline
\end{tabular}

ASA American Society of Anesthesiologist

higher than in the non-smoker group $(P=0.020)$. But the incidences were similar among patients with different smoking cessation periods. Pulmonary complications were also more commonly detected in patients who stopped smoking $\leq 2$ weeks and 2 to 4 weeks preoperatively, compared with those patients in the non-smoker group or those who had stopped smoking for $\geq 4$ weeks. There was no significant difference between the incidence of surgical site infection, bleeding, and other types of complications among each of the subgroups. In addition, when comparing the severity of complications, the $\leq 2$ weeks and $\geq 4$ weeks subgroups had significantly higher rates of major complications (grade III or greater, $P=0.040$ ). Importantly, all of the 5 patients who died within 30 days after surgery in the smoker group were among those who had ceased smoking for $\leq 2$ weeks before surgery. Although the differences were not statistically significant, smokers with smoking cessation $\leq 2$ weeks appeared to have a possible trend towards a higher risk of perioperative mortality $(5 / 823,0.6 \%)$, compared with non-smokers $(3 / 1413,0.2 \%)$ and smokers with cessation $>2$ weeks $(0 / 233)(P=0.131$ and 0.233 , respectively).
When considering the impact of cigarette dose on the incidence of complications, smokers were subsequently classified into 3 subgroups (light, moderate, and heavy smokers) according to pack-years at the 25th and 75th percentages: $\leq 20,20$ to 40 , and $\geq 40$ pack-years (Table 6). Complication rates in the light, moderate, and heavy smokers were $7.9 \%, 13.8 \%$, and $17.6 \%$, respectively. There was a positive association between the incidence of overall complications and cigarette dose. Moderate to heavy smokers (>20 pack-years) had a significantly higher risk of suffering from postoperative complications compared with light smokers ( $\leq 20$ pack-years) and non-smokers, as was the incidence of pulmonary problems. Although cigarette dose did not adversely have an impact on the incidence of bleeding and other complications, heavy smokers had a significantly increased risk of surgical site infection. However, the incidence of overall complications, surgical site infection, pulmonary problem, and the severity of complications were all comparable between the light smoker and non-smoker groups. After multivariate analysis, it was shown that the ORs for the incidences of overall complications in light, moderate, and heavy smokers were $0.963,1.478$, and 1.777 (95\%CI $0.509-1.820,1.035-2.111$, and $1.227-2.574$, respectively; $P=0.907,0.032$, and 0.002 , respectively), compared with the non-smoker group.

\section{Discussion}

Although several studies have investigated the influence of smoking and short-term preoperative smoking cessation on postoperative outcomes after various types of surgery, the overall quality of evidence is moderate and limited by the small number of studies contributing to the key analyses, leading to contradictory and perhaps even confusing conclusions [8-16, 20,25]. The majority of previous studies concluded that smoking adversely affects the short-term outcomes after surgery, and smoking cessation several weeks before surgery was effective in reducing the incidence of complications [8-12, 16].

Table 5 Postoperative complications based on the length of the smoking cessation period before surgery

\begin{tabular}{|c|c|c|c|c|c|}
\hline \multirow[t]{2}{*}{ Variables } & \multirow{2}{*}{$\begin{array}{l}\text { Non-smokers } \\
(n=1413)\end{array}$} & \multicolumn{3}{|l|}{ Smokers $(n=1056)$} & \multirow{2}{*}{$\begin{array}{l}P \\
\text { value }\end{array}$} \\
\hline & & $\leq 2$ weeks $(n=823)$ & 2 to 4 weeks $(n=40)$ & $\geq 4$ weeks $(n=193)$ & \\
\hline Complications $^{a}$ & $143(10.1 \%)$ & $115(14.0 \%)$ & $6(15.0 \%)$ & $29(15.0 \%)$ & 0.020 \\
\hline Surgical site infection & $59(4.2 \%)$ & $43(5.2 \%)$ & 0 & $14(7.3 \%)$ & 0.104 \\
\hline Pulmonary complication & $46(3.3 \%)$ & $44(5.3 \%)$ & $4(10.0 \%)$ & $6(3.1 \%)$ & 0.019 \\
\hline Bleeding & $12(0.8 \%)$ & $8(1.0 \%)$ & 0 & $4(2.1 \%)$ & 0.385 \\
\hline Others & $26(1.8 \%)$ & $20(2.4 \%)$ & $2(5.0 \%)$ & $5(2.6 \%)$ & 0.444 \\
\hline Severity of complications ${ }^{b}$ & & & & & 0.040 \\
\hline Minor (grade II) & $104(7.4 \%)$ & 80 (9.7\%) & $5(12.5 \%)$ & 17 (8.8\%) & \\
\hline Major (grade III or greater) & $39(2.8 \%)$ & $35(4.3 \%)$ & $1(2.5 \%)$ & $12(6.2 \%)$ & \\
\hline
\end{tabular}

${ }^{a}$ Data are number of complications (\%), patients may have more than one complications

${ }^{b}$ Based on the Clavien-Dindo severity classification of surgical complications 
Table 6 Postoperative complications based on pack-years of smoking before surgery

\begin{tabular}{|c|c|c|c|c|c|}
\hline \multirow[t]{2}{*}{ Variables } & \multirow{2}{*}{$\begin{array}{l}\text { Non-smokers } \\
(n=1413)\end{array}$} & \multicolumn{3}{|l|}{ Smokers $(n=1056)$} & \multirow[t]{2}{*}{$P$ value } \\
\hline & & $\leq 20$ pack-years $(n=164)$ & 20 to 40 pack-years $(n=522)$ & $\geq 40$ pack-years $(n=370)$ & \\
\hline Complications $^{a}$ & $143(10.1 \%)$ & $13(7.9 \%)$ & $72(13.8 \%)$ & $65(17.6 \%)$ & $<0.001$ \\
\hline Surgical site infection & $59(4.2 \%)$ & $6(3.7 \%)$ & $22(4.2 \%)$ & $29(7.8 \%)$ & 0.022 \\
\hline Pulmonary complication & $46(3.3 \%)$ & $2(1.2 \%)$ & $31(5.9 \%)$ & $21(5.7 \%)$ & 0.005 \\
\hline Bleeding & $12(0.8 \%)$ & $3(1.8 \%)$ & $4(0.8 \%)$ & $5(1.4 \%)$ & 0.521 \\
\hline Others & $26(1.8 \%)$ & $2(1.2 \%)$ & $15(2.9 \%)$ & $10(2.7 \%)$ & 0.367 \\
\hline Severity of complications ${ }^{b}$ & & & & & 0.001 \\
\hline Minor (grade II) & $104(7.4 \%)$ & $6(3.7 \%)$ & $52(10.0 \%)$ & $44(11.9 \%)$ & \\
\hline Major (grade III or greater) & $39(2.8 \%)$ & $7(4.3 \%)$ & $20(3.8 \%)$ & $21(5.7 \%)$ & \\
\hline
\end{tabular}

${ }^{a}$ Data are number of complications (\%), patients may have more than one complications

${ }^{b}$ Based on the Clavien-Dindo severity classification of surgical complications

In contrast, other scholars have argued that short-term smoking cessation before surgery was not associated with a decrease in wound healing and pulmonary or overall postoperative complications $[13,14,20]$. Only one study investigated the influence of preoperative smoking cessation on postoperative complications for GC patients in particular, in which Jung et al. [16] reported that postoperative complications, especially impaired wound healing, pulmonary problems, and leakage, occurred more commonly in smokers than in non-smokers. Further subgroup analysis by this research group found that smoking cessation for at least 2 weeks preoperatively was required to reduce the incidence of complications. However, their conclusions have not been verified by other studies, and the potential impact of cigarette dose has never been investigated in GC patients undergoing curative gastrectomy.

To the best of our knowledge, this is the largest study to date that has evaluated the impact of smoking on postoperative complications and the first study to investigate the attributable risk of cigarette dose on postoperative complications, basing on GC patients undergoing radical gastrectomy. According to previous studies, besides pulmonary problems, impaired wound healing and leakage were also confirmed to be significantly associated with smoking $[9,16]$. Tissue hypoxia caused by acute exposure to smoking and lacking proper fibroblast migration to form the healing tissue were considered to be the most important cause of this link [26, 27]. Moreover, heavy smokers had an obviously increased incidence of bleeding requiring transfusion, but the exact reasons for this bleeding remain to be established [10]. Thus, complications were divided into surgical site infection (including wound healing and leakage), pulmonary complication, bleeding, and others in this study, similar with that of the previous study [16]. In this study, we revealed that smoking was an independent risk factor for postoperative complications, especially pulmonary problems. All of the 65 patients developing pneumonia received antibiotic treatments, and 12 among who developed respiratory failure needing ventilation were transferred into the intensive care unit. And finally, 3 patients died due to pneumonia within 30 days after surgery. But they did not differ significantly between the smoker and non-smokers. In addition, severe smoking ( $\geq 40$ pack-years) was identified to be significantly associated with surgical site infections.

The incidences of overall complications were comparable among patients who stopped smoking $\leq 2$ weeks, 2 to 4 weeks, and $\geq 4$ weeks preoperatively. Compared with the incidence of postoperative pulmonary problems in non-smokers (3.3\%), it was comparable with that in those who stopped smoking $\geq 4$ weeks before operation (3.1\%, $P=0.914)$, but significantly higher in those who stopped smoking $<4$ weeks $(5.7 \%, P=0.007)$. Postoperative pulmonary problems have been identified to be the most costly of all major postoperative complications and resulted in the longest duration of hospital stay, as identified by the National Surgical Quality Improvement Program (NSQIP) [28]. In addition, previous studies have found that patients who underwent upper abdominal surgery were twice as likely to develop pulmonary problems than those undergoing any other surgical category [15]. Given the high incidence of and the significant adverse impact of postoperative pulmonary complications, it is very important for patients who underwent gastrectomy to quit smoking before their operation, which has been identified as a modifiable risk factor. Based on the present study, at least 4 weeks cessation may be needed to prepare for surgery, a finding consistent with the conclusion reported by Lindström et al. [12], who found that smoking cessation 4 weeks before surgery decreased the risk of complications. A meta-analysis of 6 randomized controlled trials and 15 observational studies revealed that each week of preoperative abstinence increased the relative risk reduction of postoperative complications by $19 \%$ [22]. And at least 4 weeks of smoking cessation had a significant larger 
treatment effect than shorter abstinence from smoking. Jung et al. [14] even suggested that as short as 2 weeks of smoking cessation before surgery was effective in reducing its adverse influence on surgical outcomes. One possible explanation is that the acute toxic effect of recent smoke inhalation is a major mechanism for the delayed wound healing and infection risk $[8,16]$. Thus, even short-term smoking cessation can reduce the damage caused by acute exposure to smoking and lead to a significant reduction in postoperative complications.

However, other studies have revealed that smoking cessation about half a month, 8 weeks, or even 16 weeks before surgery did not reduce the level of overall complications $[13,14,20]$. In the opinion of these researchers, the chronic cumulative effects of smoking on pulmonary functions, such as increased mucus production and a reduction in immune functions, played a more important role than acute toxic exposure, which could result in postoperative pulmonary infection or even respiratory failure [8]. It has been reported that pulmonary function generally improved after about 8 weeks of smoking cessation [25]. Thus, the optimal duration of smoking cessation prior to an operation to reduce postoperative complications remains poorly defined. Because almost all of the patients underwent surgery within 2 weeks from the diagnosis of GC in our department, the patients with smoking cessation $>2$ weeks before operation had stopped smoking when they were admitted, whereas patients with cessation time $\leq 2$ weeks were generally current smokers until they were advised to stop smoking during admission. Compared with patients with shorter preoperative smoking cessation period ( $\leq 2$ weeks), those with longer interval ( $>2$ weeks) seemed to have a higher rate of developing symptoms because of the tumor, such as bleeding and/or vomiting due to pyloric obstruction ( $26.7 \%$ vs $21.1 \%$ ), although the difference was barely outside the range of significance $(P=0.077)$. Moreover, patients with longer smoking cessation period were significantly older than those with shorter cessation interval ( 60.17 vs 56.13 years, $P<0.001)$, and with significantly lower preoperative hemoglobin levels (118.54 vs $125.05 \mathrm{~g} / \mathrm{L}, P=0.001$ ), whereas advanced age, lower hemoglobin level, and pyloric obstruction were all well-known adverse predictors for morbidity following gastrectomy $[3,5,29,30]$. Thus, we hypothesize that although the incidences of postoperative complications were comparable among patients with different smoking cessation period in the present study, the benefit of longer cessation time might be counteracted by the poorer general condition of the patients. Therefore, a prospective randomized large sample size study is needed to confirm this conjecture in the future.

In contrast to smoking status and duration of smoking cessation, the influence of smoking severity on postoperative complications has rarely been investigated. The incidence of postoperative complications was identified to be positively associated with cigarette dose in the present study, as was the surgical site infection. Pulmonary complications were also significantly more common in moderate to heavy smokers (with $>20$ pack-years). In a previous study including 20,830 cancer patients to investigate the potential effect of smoking on postoperative outcomes, Gajdos and colleagues [9] divided pack-years into quartiles and split by smoking status. Given the relatively smaller sample size of our study, we classified the smokers into 3 subgroups according to the 25th and 75th cigarette dose. As expected, major adverse events were also significantly more common in heavy smokers, compared with light to moderate smokers or non-smokers. The dose-response relationship was highly suggestive of a causal rather than a mere correlational association. The results were echoed by Hawn et al. [8], who argued that a dose-dependent relationship existed between pulmonary problems and pack-year exposure, and revealed that smoking-associated surgical complications were significantly increased in patients smoking for $>20$ pack-years. Similarly, Livingston et al. [31] found that current smoking of $>20$ pack-years was related to an increased risk of failure to wean in a series of 575 bariatric patients. In a propensity score-matched analysis of 36,454 patients who underwent plastic surgery, Toyoda et al. [10] concluded that smokers with 11 or more pack-years had significantly higher rates of deep surgical site infections and re-operation following plastic surgery. A dose-dependent association between urine nicotine levels and wound healing impairment in breast reduction patients was also found by Bartsch et al [32] The possible explanation was the chronic cumulative effects of the adverse impact of smoking, such as tissue hypoxia on pulmonary, immune, and wound healing functions [8]. This explanation was indirectly supported by the finding that a high concentration of oxygen following operation decreased the risk of wound healing problems [33]. Therefore, it was reasonable to hypothesize that a high concentration of oxygen during or after gastrectomy for heavy smokers could reduce the incidence of postoperative complications. But further study is needed to unequivocally clarify this suggestion.

The present study has a number of limitations first and foremost being that it was a retrospective and single-institution study. Thus, although smoking was identified to be an independent predictor for postoperative complications, especially pulmonary problems, it does not indicate a causal relationship and further prospective studies are needed. Second, the smoking habits and cigarette dose were only orally obtained by the responsible doctor, instead of through biological monitoring (such as nicotine metabolites), which would have been more objective. Although we recorded the average number of smoked cigarettes and the duration of 
smoking to calculate the cigarette dose, it should be borne in mind that the content of harmful substances, such as nicotine, in different types of cigarettes is likely to vary significantly, which was not investigated in detail in the present study. Therefore, there is a possibility of misclassification and miscalculation of the risk of complications in the subgroup analysis. Last but by no means the least, the basic clinicopathological characteristics were significantly different in smokers and nonsmokers, such as age and gender, which may present as confounders when investigating the relationship between smoking and postoperative complications. A prospective study or retrospective study with large samples using propensity score matching analyses to adjust the potential selecting bias may eliminate this limitation [10].

\section{Conclusions}

The present study has identified that smoking was an independent adverse predictor for postoperative complications, especially for pulmonary problems, in GC patients following radical gastrectomy. It is suggested that at least 4 weeks of smoking cessation prior to surgery is required to decrease postoperative pulmonary problems. There was a positive relationship between the incidence of complications and cigarette dose, and more than 20 pack-years were shown to increase significantly the risk of complications. Therefore, to reduce postoperative complications, both surgeons and patients should pay much attention to preoperative smoking cessation, especially for heavy smokers.

\section{Abbreviations \\ ASA: American Society of Anesthesiologists; BMI: Body mass index; $\mathrm{Cl}$ : Confidence interval; COPD: Chronic obstructive pulmonary disease; FEV1: Forced expiratory volume in $1 \mathrm{~s}$; GC: Gastric cancer; NSQIP: National Surgical Quality Improvement Program; OR: Odds ratio; TNM: Tumor, node, and metastasis; UICC: Union for International Cancer Control; VC: Vital capacity}

\section{Acknowledgements}

Not applicable.

\section{Funding}

This study received no specific grant from any funding agency in the public, commercial, or not-for-profit sectors.

\section{Availability of data and materials}

The database used and/or analyzed during the current study are not publicly available (to maintain privacy) but can be available from the corresponding author on reasonable request.

\section{Authors' contributions}

$H X$ designed the study. HX, HQ, LO, and YO collected and analyzed the data. $\mathrm{HQ}$ and LO wrote the paper. HX revised the paper. All authors have contributed to and approved the final manuscript.

\section{Ethics approval and consent to participate}

The present study was approved by the ethics committee of Hunan Cancer Hospital, and informed consent was waived considering it is a retrospective investigation and observational in nature.

\section{Consent for publication}

Not applicable.
Competing interests

The authors declare that they have no competing interests.

\section{Publisher's Note}

Springer Nature remains neutral with regard to jurisdictional claims in published maps and institutional affiliations.

\section{Author details}

${ }^{1}$ Department of Gastroduodenal and Pancreatic Surgery, Hunan Cancer Hospital and the Affiliated Cancer Hospital of Xiangya School of Medicine, Central South University, No. 283 Tongzipo Road, Changsha 410013, China. ${ }^{2}$ Central Laboratory of Hunan Cancer Hospital and the Affiliated Cancer Hospital of Xiangya School of Medicine, Central South University, No. 283 Tongzipo Road, Changsha 410013, China. ${ }^{3}$ Department of Gastroenterology and Urology, Hunan Cancer Hospital and the Affiliated Cancer Hospital of Xiangya School of Medicine, Central South University, No. 283 Tongzipo Road, Changsha 410013, China.

Received: 2 November 2018 Accepted: 26 March 2019

Published online: 02 April 2019

\section{References}

1. Bray F, Ferlay J, Soerjomataram I, Siegel RL, Torre LA, Jemal A. Global cancer statistics 2018: globocan estimates of incidence and mortality worldwide for 36 cancers in 185 countries. CA Cancer J Clin. 2018. https://doi.org/10.3322/ caac.21492.

2. Chen $W$, Zheng $R$, Baade $P D$, Zhang $S$, Zeng $H$, Bray F, Jemal $A$, Yu XQ, He J. Cancer statistics in China, 2015. CA Cancer J Clin. 2016;66(2):115-32.

3. Papenfuss WA, Kukar M, Oxenberg J, Attwood K, Nurkin S, Malhotra U, Wilkinson NW. Morbidity and mortality associated with gastrectomy for gastric cancer. Ann Surg Oncol. 2014;21(9):3008-14.

4. Hu Y, Huang C, Sun Y, Su X, Cao H, Hu J, Xue Y, Suo J, Tao K, He X, Wei H, Ying M, Hu W, Du X, Chen P. Morbidity and mortality of laparoscopic versus open D2 distal gastrectomy for advanced gastric cancer: a randomized controlled trial. J Clin Oncol. 2016;34(12):1350-7.

5. Martin AN, Das D, Turrentine FE, Bauer TW, Adams RB, Zaydfudim WW. Morbidity and mortality after gastrectomy: identification of modifiable risk factors. J Gastrointest Surg. 2016;20(9):1554-64.

6. Xiao H, Quan H, Pan S, Yin B, Luo W, Huang G, Ouyang Y. Impact of perioperative blood transfusion on post-operative infections after radical gastrectomy for gastric cancer: a propensity score matching analysis focusing on the timing, amount of transfusion and role of leukocyte depletion. J Cancer Res Clin Oncol. 2018;144(6):1143-54.

7. Sasako M, Sano T, Yamamoto S, Kurokawa $Y$, Nashimoto A, Kurita A, Hiratsuka M, Tsujinaka T, Kinoshita T, Arai K, Yamamura Y, Okajima K, Japan clinical oncology group. D2 lymphadenectomy alone or with para-aortic nodal dissection for gastric cancer. N Engl J Med. 2008; 359(5):453-62.

8. Hawn MT, Houston TK, Campaqna EJ, Graham LA, Singh J, Bishop M, Henderson WG. The attributable risk of smoking on surgical complications. Ann Surg. 2011;254(6):914-20.

9. Gajdos C, Hawn MT, Campagna EJ, Henderson WG, Singh JA, Houston T. Adverse effects of smoking on postoperative outcomes in cancer patients. Ann Surg Oncol. 2012;19(5):1430-8.

10. Toyoda Y, Fu RH, Li L, Otterburn DM, Rohde CH. Smoking as an independent risk factor for postoperative complications in plastic surgical procedures: a propensity score-matched analysis of 36,454 patients from the NSQIP database from 2005 to 2014. Plast Reconstr Surg. 2018;141(1):226-36.

11. Atilla N, Arpag H, Bozkus F, Kahraman H, Cengiz E, Bulbuloglu E, Atilla S. Can we predict the perioperative pulmonary complications before laparoscopic sleeve gastrectomy: original research. Obes Surg. 2017;27(6):1524-8.

12. Lindström D, Sadr Azodi O, Wladis A, Tønnesen H, Linder S, Nåsell H, Ponzer S, Adami J. Effects of a perioperative smoking cessation intervention on postoperative complications: a randomized trial. Ann Surg. 2008;248(5): 739-45.

13. Sørensen LT, Jørgensen T. Short-term pre-operative smoking cessation intervention does not affect postoperative complications in colorectal surgery: a randomized trial. Color Dis. 2003;5(4):347-52.

14. Rodriquez M, Gómez-Hernandez MT, Novoa N, Jiménez MF, Aranda JL, Varela G. Refraining from smoking shortly before lobectomy has no 
influence on the risk of pulmonary complications: a case-control study on a matched population. Eur J Cardiothorac Surg. 2017;51(3):498-503.

15. Scholes RL, Browning L, Sztendur EM, Denehy L. Duration of anaesthesia, type of surgery, respiratory co-morbidity, predicted VO2max and smoking predict postoperative pulmonary complications after upper abdominal surgery: an observational study. Aust J Physiother. 2009;55(3):191-8.

16. Jung KH, Kim SM, Choi MG, Lee JH, Noh JH, Sohn TS, Bae JM, Kim S. Preoperative smoking cessation can reduce postoperative complications in gastric cancer surgery. Gastric Cancer. 2015;18(4):683-90.

17. Amin MB, Edge SB, Greene FL, Brierley JD. AJCC cancer staging manual. 8th ed. New York: Springer; 2017.

18. Japanese Gastric Cancer Association. Japanese gastric cancer treatment guidelines 2014 (ver. 4). Gastric Cancer. 2017;20(1):1-19.

19. Xiao H, Xiao Y, Quan H, Liu W, Pan S, Ouyang Y. Intra-abdominal infection after radical gastrectomy for gastric cancer: incidence, pathogens, risk factors and outcomes. Int J Surg. 2017:48:195-200.

20. Myers K, Hajek P, Hinds C, Mcrobbie H. Stopping smoking shortly before surgery and postoperative complications; a systemic review and metaanalysis. Arch Inter Med. 2011;171(11):983-9.

21. Sørensen LT. Wound healing and infection in surgery. The clinical impact of smoking and smoking cessation: a systematic review and meta-analysis. Arch Surg. 2011;147(4):373-83.

22. Mills E, Eyamo O, Lockhart I, Kelly S, Wu P, Ebbert JO. Smoking cessation reduces postoperative complications: a systematic review and meta-analysis. Am J Med. 2011;124(2):144-54.

23. Dindo D, Demartines N, Clavien PA. Classification of surgical complications: a new proposal with evaluation in a cohort of 6336 patients and results of a survey. Ann Surg. 2004;240(2):205-13.

24. Aoyama T, Yoshikawa T, Sato T, Hayashi T, Yamada T, Oqata T, Cho H. Equivalent feasibility and safety of perioperative care by ERAS in open and laparoscopy-assisted distal gastrectomy for gastric cancer: a singleinstitution ancillary study using the patient cohort enrolled in the JCOG0912 phase III trial. Gastric Cancer. 2018. https://doi.org/10.1007/ s10120-018-0873-3.

25. Thomsen T, Villebro N, Møller AM. Interventions for preoperative smoking cessation. Cochrance Database Syst Rev. 2014;27(3):CD002294.

26. Belda FJ, Aguilera L, García de la Asunción J, Alberti J, Vicente R, Ferrándiz L, Rodríguez R, Company R, Sessler DI, Aguilar G, Botello SG, Ortí R, Spanish Reduccion de la Tasa de Infeccion Quirurgica group. Supplemental perioperative oxygen and the risk of surgical wound infection: a randomized controlled trial. JAMA. 2005;294(16):2035-42.

27. Wong LS, Martins-Green M. Firsthand cigarette smoke alters fibroblast migration and survival: implications for impaired healing. Wound Repair Regen. 2004;12(4):471-84.

28. Dimick JB, Chen SL, Taheri PA, Henderson WG, Khuri SF, Campbell DA Jr. Hospital costs associated with surgical complications: a report from the private-sector National Surgical Quality Improvement Program. J Am Coll Surg. 2004;199(4):531-7.

29. Jung DH, Lee HJ, Han DS, Sun YS, Kong SH, Lee KU, Yang HK. Impact of perioperative hemoglobin levels on postoperative outcomes in gastric cancer surgery. Gastric Cancer. 2013;16(3):377-82.

30. Huang CM, Tu RH, Lin JX, Zheng CH, Li P, Xie JW, Wang JB, Lu J, Chen QY, Cao LL, Lin M. A scoring system to predict the risk of postoperative complications after laparoscopic gastrectomy for gastric cancer based on a large-scale retrospective study. Medicine (Baltimore). 2015;94(17):e812.

31. Livingston EH, Arterburn D, Schifftner TL, Henderson WG, DePalma RG. National surgical quality improvement program analysis of bariatric operations: modifiable risk factors contribute to bariatric surgical adverse outcomes. J Am Coll Surg. 2006:203(5):625-33.

32. Bartsch RH, Weiss G, Kästenbauer T, Patocka K, Deutinger M, Krapohl BD, Benditte-Klepetro HC. Crucial aspects of smoking in would healing after breast reduction surgery. J Plast Reconstr Anesthet Surg. 2007;60(9):1045-9.

33. Greif R, Akca O, Horn EP, Kurz A, Sessler DI, Outcome Research Group. Supplemental perioperative oxygen to reduce the incidence surgicalwound infections. N Engl J Med. 2000;342(3):161-7.

\section{Ready to submit your research? Choose BMC and benefit from:}

- fast, convenient online submission

- thorough peer review by experienced researchers in your field

- rapid publication on acceptance

- support for research data, including large and complex data types

- gold Open Access which fosters wider collaboration and increased citations

- maximum visibility for your research: over $100 \mathrm{M}$ website views per year

At BMC, research is always in progress.

Learn more biomedcentral.com/submissions 